\title{
Comunicación política en Ecuador.
}

Análisis de la presencia en medios sociales de los asambleístas ecuatorianos

\section{Political communication in Ecuador. Analysis of the presence of Ecuadorian national assembly members in social media}
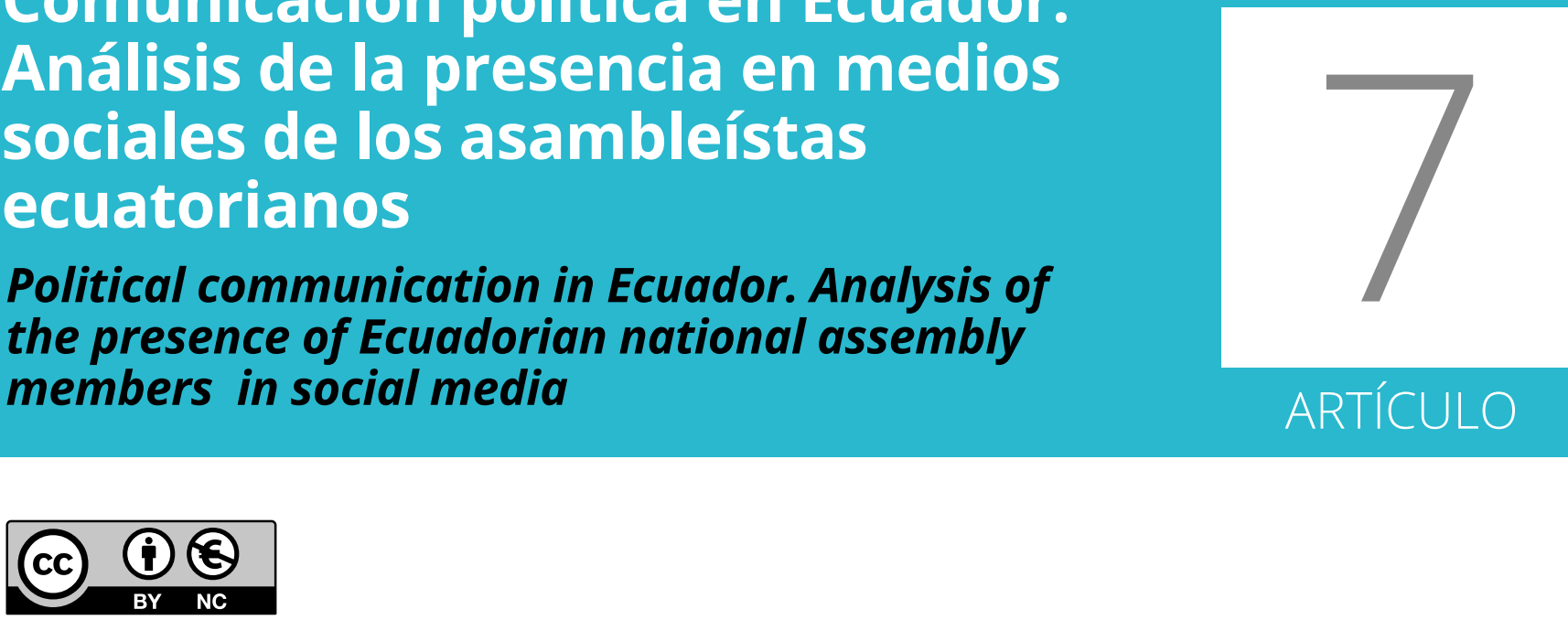

\section{Javier Vire Riascos}

Universidad de Málaga

Comunicador Organizacional con Maestría en Dirección Estratégica e Innovación de la Comunicación, Doctorando en la Universidad de Málaga.

javiervireriascos@gmail.com

ORCID: 0000-0002-0847-9322

Fecha de recepción: 19 de julio de 2018 / Aceptación: 3 de septiembre de 2018

\section{Resumen}

El estudio parte de los perfiles que cada asambleísta tiene en el sitio web de la Asamblea Nacional, donde a más de un correo electrónico y un blog corporativos, los legisladores pueden enlazar sus perfiles de redes sociales. Se analiza la presencia de los 137 parlamentarios en términos de medios en los que participa, número de seguidores y frecuencia de publicaciones propias en el período octubre 2017 - enero 2018. El estudio se basa en las cuentas enlazadas en el sitio web de la Asamblea Nacional, porque busca conocer las vías oficiales con las que la ciudadanía puede interactuar con ellos.

\section{PALABRAS CLAVE}

Comunicación política, medios sociales, asambleístas, Ecuador, ciberpolítica.

\section{Abstract}

We studied the profiles of assembly members on the website of the National Assembly, where we found email addresses, corporate blogs and social media profiles. The presence of the 137 parliamentarians was analysed in terms of the media in which they participate, their number of followers and the frequency of their publications in the period October 2017 - January 2018. Our research focuses on the accounts linked on the website of the National Assembly, because we wished to discover official channels for citizens to contact assembly members. 


\section{INTRODUCCIÓN}

Las tecnologías de información y comunicación (TIC) representan una herramienta para una comunicación más participativa y simétrica que permite un diálogo constante, rompiendo limitaciones de espacio y tiempo, interrelacionando a los antiguos emisor-receptor y generando una comunicación bidireccional de interés para los participantes.

La relación entre las instituciones y la ciudadanía es uno de los campos que mayor beneficio puede encontrar con la utilización de las TIC, por lo tanto se ha investigado la participación y el uso que los asambleístas ecuatorianos hacen de los medios sociales.

La Asamblea Nacional de Ecuador es la institución legislativa del país, está compuesta por 137 asambleístas, 15 nacionales, 6 del exterior (representantes de los ciudadanos migrantes) y 116 representantes de las 24 provincias del país. Según el movimiento político al que pertenecen, la (Asamblea Nacional República del Ecuador, 2018) reconoce los siguientes movimientos: Alianza País, Alianza País-Unidad Primero, Movimiento CREO, Movimiento SUMA, Otros Movimientos, PSC/Madera de Guerrero, Pachakutik, Sociedad Patriótica y Tiempo de Cambio/PSC. (Tabla 1)

Según la Asamblea Nacional los 137 asambleístas se agrupan de acuerdo al movimiento político por el que fueron elegidos, siendo los movimientos Alianza País, CREO y PSC/Madera de Guerrero los que tienen mayor número de legisladores, tal como lo muestra la Tabla Nro. 1.
Tabla 1. Distribución de asambleístas por movimiento político

\begin{tabular}{|c|c|c|}
\hline MOVIMIENTO POLítico & $\begin{array}{c}\text { Número } \\
\text { de Asam- } \\
\text { bleístas }\end{array}$ \\
\hline Alianza País & 66 & 48.17 \\
\hline Alianza País-Unidad Primero & 8 & 5.84 \\
\hline Movimiento CREO & 30 & 21.90 \\
\hline Movimiento SUMA & 3 & 2.19 \\
\hline Otros Movimientos & 8 & 5.84 \\
\hline PSC/Madera de Guerrero & 14 & 10.22 \\
\hline Pachakutik & 5 & 3.65 \\
\hline Sociedad Patriótica & 2 & 1.46 \\
\hline Tiempo de Cambio-PSC & 1 & 0.73 \\
\hline
\end{tabular}

Fuente. Elaboración propia

El objetivo del estudio es conocer en qué medios sociales participan los asambleístas ecuatorianos, con qué frecuencia publican, cuántos seguidores tienen en sus cuentas, cuál ha sido el comportamiento de publicación en los cuatro meses estudiados y plantear una comparación con los resultados de un estudio similar realizado en España.

Para el efecto se han revisado los perfiles en el sitio web de la Asamblea Nacional de los 137 asambleístas, así como las redes sociales en las que participan, analizando más de 15.000 publicaciones principalmente de Facebook y Twitter. 


\section{MARCO TEÓRICO}

\subsection{COMUNICACIÓN POLÍTICA}

La comunicación ha sido históricamente un elemento de poder, tanto que es considerado como un poder intrínseco de la sociedad. Se ha emitido desde los medios de comunicación para informar a la población por parte de las autoridades, pero los medios también han servido de vehículo para la emisión de mensajes (peticiones, protestas, participación) de los ciudadanos. Sin embargo, se ha ejercido el modelo tradicional emisor-mensaje-receptor que, en muchas ocasiones no generaba impacto o que en el mejor de los casos era escuchado por el receptor.

Al respecto, (Grunig \& Hunt, 1984) proponen el modelo simétrico bidireccional de comunicación que no es otra cosa que dinamizar el proceso tradicional, no concentrando la emisión a una parte del proceso sino generando diálogo de manera que el receptor sea también emisor y aquel modelo vertical, monolítico y simplista se convierta en horizontal, participativo, equilibrado y generador de valor.

Este tipo de comunicación es fácilmente practicable en las relaciones interpersonales, pero para aplicarlo a mayores segmentos se necesita de otros recursos como nuevos canales de comunicación. Internet se ha convertido en ese canal utilizado por todos, incluso por los medios de comunicación, para tener una participación activa sin límites de tiempo o espacio, a través de sitios web 2.0, redes sociales y otras aplicaciones que permiten conocer, compartir, participar, proponer, en definitiva dialogar con otras personas, instituciones, empresas sobre temas que son de interés común.
Conceptualizar la comunicación política ha sido intención de varios autores a lo largo de la historia, desde diversos puntos de vista como el jurídico, sociológico y comunicacional. Así, (Canel, 1999) hace un recorrido por los criterios de varios autores que relacionan principalmente a la comunicación política como una actividad propia del estado, las instituciones públicas y los medios de comunicación, sin contar a otros actores como organizaciones profesionales, gremiales, sociales, ONG y ciudadanía en general.

Es evidente que en la actualidad la participación de organizaciones y ciudadanía es parte de la comunicación política, pero en criterio de (Pérez, 2009) es necesario conocer la manera de orientar a la sociedad a superar la estructura de los medios masivos en la comunicación y encontrar nuevos escenarios para la participación democrática de la sociedad, como respuesta de este planteamiento el internet en general y las redes sociales en particular son un instrumento indiscutible para facilitar las comunicación y participación de la sociedad en la comunicación política.

\subsection{MEDIOS SOCIALES Y CIBERPOLÍTICA}

El concepto de comunicación 2.0 radica en la posibilidad de generar diálogo entre el antiguo emisor (empresa, institución, político, etc.) y sus públicos, es decir practicar la bidireccionalidad en la comunicación de la que se habló anteriormente. En palabras de (Coterón Molina, 2016) con la comunicación 2.0 se ha pasado de la información a la interacción donde la conversación es la protagonista en un modelo que permite crear sinergias entre los participantes de la conversación.

La principal aportación de la tecnología a la comunicación política es la interactividad, así 
como otras ventajas como rapidez, comodidad, capacidad de actualización y almacenamiento, utilización de recursos multimedia y predisposición del público, según (Castillo \& Almansa, 2014).

En la actualidad se habla ya de web 3.0 y más, pero el gran cambio que supuso la posibilidad de interacción en relación a la comunicación de aquellos sitios web lineales y totalmente informativos que casi ya no existen, fue lo que significó el inicio de esta participación que trajo consigo la creación de blogs y diversas redes sociales, que han experimentado varios cambios en sus estructuras y formalidades de presentación.

Los blogs son bitácoras o espacios online, generalmente temáticos, utilizados principalmente por personas naturales para escribir sobre ciertos asuntos de interés común para un grupo de personas o instituciones. Las empresas también comenzaron a utilizar los blogs corporativos como una forma alterna de comunicarse con sus públicos, además de sus webs oficiales, pues un blog es mucho más cercano a sus públicos y se convirtió como asegura (Menéndez, 2008) en la cara humana de las empresas, precisamente por su capacidad de interacción con los usuarios.

Poco tiempo después se potenciaron las redes sociales, que ya existían pero tenían un uso limitado, el boom de las redes sociales hizo que los blogs vayan perdiendo presencia y aunque aún existen, cada vez son menos en utilización, seguidores e influencia.

La campaña electoral de Barak Obama en 2008 se ha considerado como un punto de inflexión en la comunicación política, el uso de las herramientas 2.0 y su combinación con el marketing le permitió tener un efecto doble: la participación de sus electores que pudieron acceder a sus discursos, ser invitados a sus eventos elec- torales, establecer propuestas, mensajes e incluso donaciones; y generar una base de datos con información privilegiada de sus electores, que la usó en la campaña de reelección en 2012, como lo indican (Monteiro, Vera, \& Vaca Narvaja, 2017).

El debate político ha pasado de la reunión física de partidarios a la discusión generalizadas a través de redes sociales, donde las conversaciones políticas entre los usuarios son muy intensas y profundas. Es necesario que las agrupaciones políticas y las autoridades en funciones sean parte de ese debate, exponiendo sus puntos de vista pero también escuchando los argumentos de los usuarios (partidarios o no) sobre sus propuestas y gestión gubernamental. Pero a los actores políticos les cuesta entrar en esta dinámica no aprovechan esta forma de interactuar, manteniendo la actitud pasiva de las reuniones de militancia y utilizando las redes sociales sólo con fines informativos pero no de enriquecimiento mutuo de ideas, propuestas y participaciones (Gutiérrez-Rubí, 2015).

La red social más popular en el planeta es Facebook, es la segunda web en audiencia, superada solamente por Google. Las características de esta red social se identifican en lo personal de la comunicación de cada usuario, en el protagonismo del mensaje sobre el receptor ya que el mensaje llega sin necesidad de ser buscado, la poca vigencia de los mensajes porque dependiendo de la actividad de la red de amigos las publicaciones pueden ser vistas o no. Se trata de una red social muy potente porque permite captar seguidores a través de la opción "me gusta" y de la facilidad acceder a las publicaciones incluso sin ser contactos directos a través de las publicaciones compartidas por otros contactos (Tuñez \& Sixto, 2011). Facebook, sin embargo, está sufriendo un envejecimiento de sus usuarios, ya que los jóvenes prefieren otros 
tipos de redes sociales, según varios estudios realizados; eso también contribuye a que en el aspecto político sea una red social interesante porque permite llegar a un público que es totalmente activo en las decisiones e incluso en la administración política de un país.

En 2006 nació otra plataforma que tiene como características la síntesis de sus publicaciones, Twitter permitió inicialmente hasta 140 caracteres y actualmente ha duplicado el número, principalmente para acoplarse a diversos idiomas, a pesar de ello, lo directo de los mensajes sigue siendo su principal característica, así como la posibilidad de crear tendencias sobre un tema específico con la utilización de hashtags.

La participación en Twitter es más específica respecto a otras redes sociales, es decir sus contenidos son temáticos y requieren de conocimiento y experiencia sobre un tema determinado (Gómez Céspedes, 2016). Ha sido utilizada también como una red informativa, donde se publican titulares y enlaces al contenido de informaciones de los medios de comunicación. En política, Twitter es una de las herramientas más utilizadas, pues su posibilidad de participación entre los seguidores, de responder los tuits, de compartirlos mediante RT y de generar hilos de diálogo a partir de una publicación, son características de bidireccionalidad en la comunicación.

Instagram es una red principalmente utilizada por jóvenes, el 90\% de los usuarios tienen menos de 35 años de edad, sus características de movilidad y visualización, contrario a lo textual de las otras redes sociales, ha influido para que el público joven la prefiera. Es la red social con mayor crecimiento en los últimos años con más de 700 millones de usuarios en 2017, según información de la misma aplicación, ubicándose detrás de Facebook y relegando a Twitter al tercer lugar de las redes sociales (Selva-Ruiz \& Caro-Castaño, 2017).

El público joven de instagram es también un público objetivo para el análisis de la relación de autoridades y políticos, porque abarca distintas edades de personas facultadas para ejercer el voto y de otras personas que sin cumplir la mayoría de edad, tienen voto facultativo como es el caso de Ecuador. Además estos usuarios son los más activos en redes sociales.

Cada red social tiene características propias que la hacen diferente a las otras, aunque hay usuarios de varias redes sociales, en general, los perfiles y las expectativas que cada uno tiene es diferente en cada red social. Instagram, por ejemplo, tiene un público más joven que Facebook. Por eso los contenidos que se publican en cada red social deben ser adaptados a las particularidades de ésta y al perfil de público con el que se comunica. Es frecuente encontrar que una misma publicación (texto, imagen, audiovisual) es publicada en varias redes sociales de una empresa o persona, limitando así el impacto y la generación de valor en la comunicación.

Los juegos son en la actualidad una de las formas de comunicarse con los usuarios en redes sociales, principalmente en instagram, donde está la "generación gamer", que es criterio de (Gutiérrez-Rubí, 2015) un grupo de personas con características proactivas y dinámicas que buscan generar experiencias interesantes que les represente retroalimentación, sociabilidad y experiencia gratificante.

En definitiva, los medios sociales permiten ventajas importantes a los actores políticos y autoridades para comunicarse con la ciudadanía, que Criado y Martínez Fuentes, citados por (Castillo \& Almansa, 2014) hacen hincapié en la reducción de las distancias entre el líder y sus seguidores, la posibilidad de incrementar 
el diálogo interactivo entre ellos y la apariencia de escucha del líder de los comentarios de sus seguidores.

\section{METODOLOGÍA}

El estudio se realiza a partir del sitio web de la Asamblea Nacional del Ecuador, para conocer el uso de los medios sociales durante los meses de octubre 2017 a enero 2018, por parte de los asambleístas ecuatorianos que cumplen sus funciones en el período 2017 - 2021. El sitio web de la Asamblea Nacional mantiene un perfil de cada asambleísta en donde está su correo electrónico, un blog corporativo y un espacio destinado a los enlaces a otros blogs y a perfiles de cuentas en redes sociales que mantenga cada asambleísta. La investigación parte desde los enlaces situados en el sitio web de la Asamblea Nacional porque se busca conocer los canales oficiales que tienen los asambleístas para comunicarse con la ciudadanía.

Se analiza la gestión del blog corporativo de cada asambleísta en el sitio web de la Asamblea Nacional, así como la participación en otros blogs y cuentas de redes sociales que los asambleístas hayan enlazado. El objeto del estudio es conocer los medios sociales en los que participan los asambleístas ecuatorianos, número de seguidores, frecuencia de publicaciones y cantidad de publicaciones por mes estudiado.

Se ha aplicado la técnica de análisis de contenidos a cada perfil del blog corporativo de la Asamblea Nacional, como de los perfiles de redes sociales enlazadas por cada asambleísta. En el estudio se toma en cuenta únicamente las publicaciones propias, sin contar el contenido compartido o retuiteado de otros perfiles, ya que se pretende medir la producción propia del perfil del asambleísta.
Con los datos obtenidos de los perfiles de los 137 asambleístas, se presenta información sobre su participación en los medios sociales, analizados en forma general, así como agrupados por movimiento político y por sexo.

Para efectos del estudio se han considerado cuatro grupos de movimientos políticos: Alianza País y Alianza País-Unidad Primero dado que este último es una alianza específica en la provincia de Manabí, se denotará como AP. Movimiento CREO y Movimiento SUMA dado que conformaron alianza electoral, se denotará como CREO-SUMA. PSC/Madera de Guerrero que se denotará como PSC/MG y los restantes movimientos políticos agrupados como OTROS.

Estudios similares se han realizado en otros países, específicamente en España, por tanto se presenta también un análisis comparativo con los resultados obtenidns en dicho país.

Durante la investigación se encontró el caso de 10 perfiles que, por la alta cantidad de publicaciones que realizan, no se pudo acceder con exactitud al número de publicaciones en Facebook y/o Twitter durante alguno de los meses estudiados.

\section{RESULTADOS}

La Asamblea Nacional de Ecuador presenta en su sitio web la página PLENO-ASAMBLEÍSTAS en donde se encuentra el perfil de cada asambleísta con su nombre, movimiento político, provincia a la que representa, su blog corporativo y un espacio denominado "sígueme en" donde el asambleísta puede enlazar los perfiles de sus cuentas en medios sociales. 


\subsection{BLOG CORPORATIVO}

El blog corporativo de la Asamblea Nacional de Ecuador tiene características netamente informativas, tanto por el uso que hacen los asambleístas como por su diseño, el mismo que no cuenta con un espacio para comentarios o retroalimentación de los lectores.

El 70\% de los asambleístas han utilizado (al menos en una ocasión) el blog corporativo de la Asamblea Nacional, mientras 41 asambleístas que representan el 30\% no han intervenido en este espacio, sin embargo, de los 96 asambleístas que sí intervienen, 34 lo han hecho fuera del período estudiado.

En definitiva, entre octubre 2017 y enero 2018, 62 asambleístas (45\%) registran alguna participación en el blog corporativo. De ellos sólo 5 postean más de dos publicaciones semanales, 35 lo hacen quincenal o mensualmente y 22 publican eventualmente o sea con una frecuencia mayor a un mes. Estos resultados denotan el poco interés de los asambleístas por utilizar este recurso existente en el sitio web de la Asamblea Nacional y que es el primer enlace de un ciudadano con un asambleísta a través de este portal.

Los 5 asambleístas que postean frecuentemente son de $\mathrm{AP}$, que por otra parte tiene una

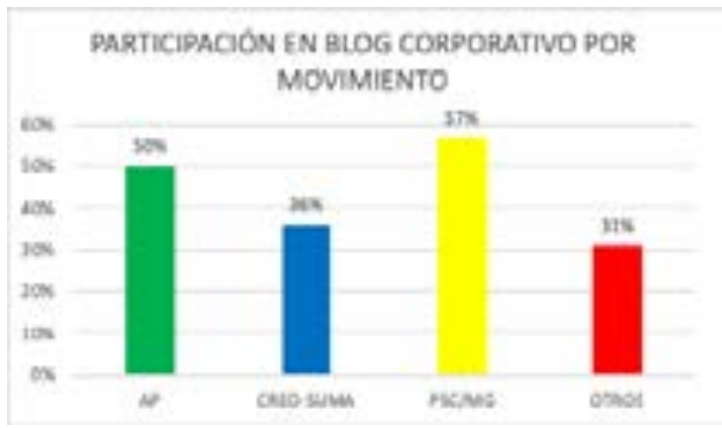

Figura 1. Participación en Blog Corporativo por movimiento político. Elaboración propia participación general en el blog del 50\% de sus asambleístas, menor que el movimiento PSC/ MG que con el 57\% de sus asambleístas, es el bloque porcentualmente más participativo en este espacio. CREO-SUMA tiene una participación del 36\% de sus asambleístas y los integrantes de los restantes movimientos políticos participan en un 31\%, conforme lo muestra el Gráfico Nro. 1.

El 58\% de las asambleístas mujeres participan en el blog corporativo, frente al 37\% de los varones. La tendencia en la frecuencia de publicación es similar entre hombres y mujeres, la mayoría (61\% de ellas y el 52\% de ellos) publican quincenal o mensualmente.

\subsection{BLOG PERSONAL}

El blog es una herramienta poco utilizada por los asambleístas ecuatorianos, sólo el 12\% que significa 16 asambleístas enlazan un blog personal. De ellos el 50\% pertenecen a AP, lejos del $12.5 \%$ de CREO-SUMA y PSC/MG, el otro $25 \%$ es de los asambleístas de otros bloques parlamentarios.

Si el interés por utilizar un blog es precario, la gestión de quienes lo enlazan lo es más. Ningún asambleísta postea al menos dos veces por semana como es la recomendación general de los expertos, sino que la mayoría (56\%) lo hace con una frecuencia mayor a un mes. Sólo 3 asambleístas publican una vez por semana, los demás lo hacen mensualmente o en un período más largo.

Existe un solo blog que provoca comentarios de los lectores, la gran mayoría escribe sus publicaciones en tono informativo y unidireccional. También hay perfiles que muestran el icono del blog pero su enlace está roto o direcciona a cuentas de Facebook o Twitter, en 
dichos casos se ha considerado como inexistente el enlace.

Los blogs que tienen actividad mayor a un mes, en su mayoría tienen fecha de última publicación anterior a octubre 2017 e inclusive corresponden a contenidos y fechas de la campaña política, entendiéndose que han sido utilizados solamente como instrumento de campaña mas no como de comunicación permanente.

\subsection{REDES SOCIALES}

Los perfiles de medios sociales enlazados por los asambleístas ecuatorianos son mayoritariamente de Facebook (61\%) y Twitter (56\%). En menor cantidad está instagram (20\%), youtube (18\%) y otras redes sociales como flickr, soundclound y google+ tienen valores ínfimos.

Instagram es una plataforma que ha crecido considerablemente en el número de cuentas activas, teniendo un perfil de usuario joven ya que es una red netamente visual. La escasa participación en instagram por parte de los asambleístas o su equipo de comunicación, deja ver el escaso interés por comunicarse con el ciudadano joven del país. De los veintiocho asambleístas que participan en esta red, diez publican diariamente, ocho lo hacen de forma semanal y nueve con frecuencia de un mes o más.

El $61 \%$ de los asambleístas que participan en instagram pertenecen al movimiento AP, 17\% a CREO-SUMA y el mismo porcentaje a PSC/ MG. Mientras que de los diez asambleístas que interactúan diariamente 6 son de AP, 2 de CREO-SUMA y 2 de PSC/MG.

Finalmente de los 28 asambleístas activos en instagram, el 39\% están en el rango entre 1.001 y 5.000 seguidores, 28\% tienen menos de 500 y $18 \%$ tienen más de 10.000 seguidores.

Respecto de Youtube 18 asambleístas enlazan su cuenta, de los cuales el $72 \%$ tienen menos de 500 seguidores y el 60\% publica con una frecuencia mayor a un mes. Estos datos dejan clara la escasa participación e interacción a través de esta red, que es utilizada más bien como un depósito de vídeos que han sido lanzados por otros medios.

Al igual que con los blogs, existen iconos de cuentas de redes sociales que redireccionan a la plataforma en general o sencillamente no tienen enlace definido, lo que se considera como no enlazado.

\subsubsection{FACEBOOK}

Facebook es la red en la que participa el mayor número de asambleístas ecuatorianos, 84 legisladores enlazan su perfil al sitio web de la Asamblea Nacional, de los cuales el 62\% son hombres y el 38\% mujeres. Por otra parte, existe paridad en la proporción de asambleístas hombres y mujeres que participan en esta red (62\% de hombres y $60 \%$ del total de mujeres).

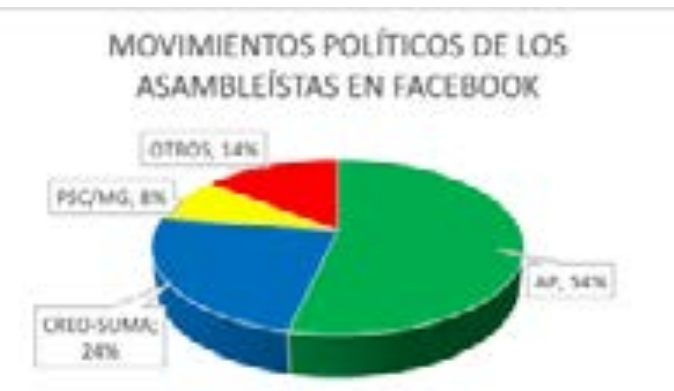

Figura 2. Movimientos políticos de los asambleístas que enlazan Facebook. Fuente: Elaboración propia 
Los asambleístas que enlazan la su cuenta de Facebook pertenecen mayoritariamente a AP, luego están los de la alianza CREO-SUMA, PSC/ MG y minoritariamente de otras agrupaciones políticas, como se indica en el Gráfico Nro.2. Mientras que la participación en Facebook por partido político con respecto del total de sus asambleístas existe un empate entre AP y CREO/SUMA con el 61\%, PSC/MG tiene el 50\% de los asambleístas y el 75\% de los asambleístas de otros movimientos políticos.

El 36\% de los asambleístas que enlazan Facebook, tienen una comunidad de más de 10.000 seguidores. Entre 5.001 y 10.000 está el 25\%, el mismo porcentaje tiene entre 1.001 y 5.000 seguidores y el $15 \%$ restante tiene menos de 1.000 seguidores.

En Facebook se han analizado más de 7.000 publicaciones en el periodo estudiado, encontrando que el $71 \%$ de los asambleístas publican diariamente, el 18\% lo hace entre 1 y 3 veces a la semana y el $7 \%$ con frecuencia mayor a un mes. Los principales contenidos publicados son de carácter informativo y partidista, predominando imágenes de las entrevistas en medios de comunicación, intervenciones en el pleno de la asamblea y reuniones con sus líderes de movimiento político.

Tabla 2. Promedios de publicación en facebook

\begin{tabular}{|c|c|}
\hline MOVIMIENTO & PROMEDIO \\
\hline AP & 1.04/día \\
\hline CREO-SUMA & 0.65/día \\
\hline $\mathrm{PSC} / \mathrm{MG}$ & 0.89/día \\
\hline OTROS & 0.65/día \\
\hline
\end{tabular}

Fuente: Elaboración propia
El promedio general de publicaciones calculado es de 0.90 diarias en Facebook, encontrando valores extremos como el 0.025/día de un asambleísta de OTROS MOVIMIENTOS y el 2.67/día de un asambleísta de AP. El promedio general es menor al recomendado entre 1 y 2 publicaciones diarias. Por cada movimiento político los promedios obtenidos se muestran en la Tabla Nro. 2.

En los cuatro meses estudiados se realizaron 7.388 publicaciones en Facebook siendo enero de 2018 el mes con mayores publicaciones (34\%), esta situación se explica en que fue un mes previo a las votaciones en la Consulta Popular, lo que se ratifica con el contenido partidista que mayoritariamente se publicó en este mes. Noviembre 2017 con el 25\% fue el segundo mes con mayores publicaciones. Octubre con el 22\% y diciembre con el 19\% complementan el total de publicaciones.

\subsubsection{TWITTER}

Twitter es la red en la que los legisladores ecuatorianos se muestran más participativos, no por el número de asambleístas que enlazan su perfil de esta plataforma, sino por el número de publicaciones en el periodo estudiado. A pesar que la participación en número de asambleístas en Twitter (56\%) es menor que en Facebook (61\%), el número de publicaciones propias es mayor (7.912 en Twitter vs. 7.388 en Facebook).

El total de asambleístas que enlazan su cuenta de Twitter (77), está formado por el 57\% hombres y $43 \%$ mujeres. Mientras que la participación por sexo indica que en Twitter están activos el $62 \%$ de las asambleístas mujeres y el 52\% de los hombres. (Figura 3) 


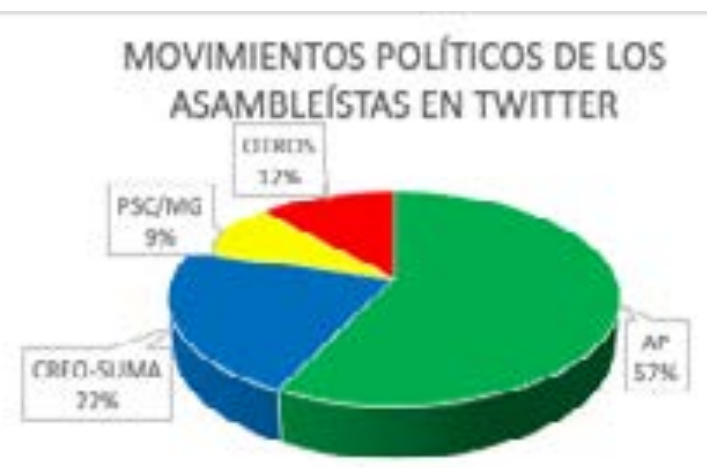

Figura 3. Movimiento político de los asambleístas que enlazan Twitter. Fuente: Elaboración propia

AP con 44 perfiles es el movimiento político que aporta con el mayor número de asambleístas en Twitter, seguido de CREO-SUMA con 17 asambleístas activos, ver Gráfico Nro. 3. Respecto del número de asambleístas por movimiento: AP tiene el 59\% activos en Twitter, CREO-SUMA el 52\% y PSC/MG el 50\% de sus asambleístas.

En número de seguidores, el 34\% de asambleístas están el rango de 1.001 a 5.000 seguidores, el 32\% tienen más de 10.000, al 14\% de asambleístas los siguen entre 5.001 - 10.000 usuarios y el 19\% de asambleístas tienen menos de 1.000 seguidores en sus cuentas de Twitter.

Los perfiles de las asambleístas mujeres son los que tienen más seguidores, así en el rango de más de 10.000, las mujeres representan el 52\% sobre el $48 \%$ de los hombres, lo que gana en representatividad al recordar en general que hay menos asambleístas mujeres que hombres, tendencia que se mantiene en las cuentas de Twitter enlazadas. En el rango de 5.001 a 10.000 las mujeres tienen el 54\%. Los hombres, por su parte, dominan los rangos de 1.001 a 5.000 seguidores con el 62\% y el de menos de 1.000 seguidores con el $73 \%$. (Figura 4)

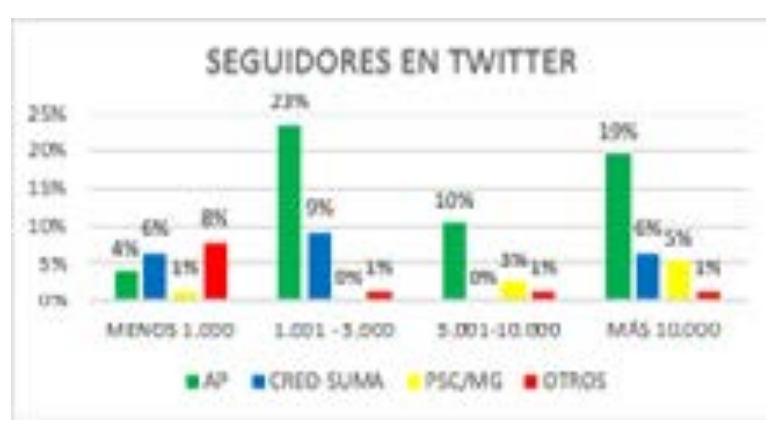

Figura 4. Número de seguidores por movimiento político. Fuente: Elaboración propia

En general, AP es el movimiento con mayor número de seguidores. El 19\% del total de asambleístas en Twitter son de este movimiento político y tienen más de 10.000 seguidores y el 23\% también son de AP y están en el rango de 1.001 a 5.000 seguidores, lo que es lógico pues es el movimiento con mayor número de asambleístas que enlazan su perfil, ver Gráfico Nro. 4. Sin embargo, un dato importante es el caso del movimiento PSC/MG que el $57 \%$ de sus asambleístas tienen más de 10.000 seguidores, siendo el movimiento relativamente más seguido. Claro, este valor en números absolutos es muy bajo, pues son 4 de 7 asambleístas activos en Twitter que tiene el movimiento.

De los 77 asambleístas que enlazan su cuenta de Twitter, el 82\% publica diariamente, el 14\% lo hace de 1 a 3 veces por semana y el 4\% con frecuencia mayor a un mes. El $77 \%$ de los asambleístas hombres y el $88 \%$ de las mujeres publican todos los días en Twitter. Entre tanto el $86 \%$ de los asambleístas de AP y el $85 \%$ de los de PSC/MG también publican todos los días. (Tabla 3)

Analizados las 7.912 publicaciones de los asambleístas entre octubre 2017 y enero 2018, el promedio general de tuits/día es de 0,998. 
Tabla 3. Promedio de tuits/día por movimiento político

\begin{tabular}{|c|c|}
\hline MOVIMIENTO & PROMEDIO \\
\hline AP & 1,100/día \\
\hline CREO-SUMA & 0,952/día \\
\hline PSC/MG & 1,322/día \\
\hline OTROS & 0,935/día \\
\hline
\end{tabular}

Fuente: Elaboración propia

Teniendo el valor más alto una asambleísta de CREO-SUMA con un promedio de 2.883 tuits/ día y siendo el valor más bajo 0,016 que también corresponde a un asambleísta del mismo movimiento político. El movimiento PSC/MG es el que tiene mayor promedio de tuits/día, seguido de AP, tal como se aprecia en la tabla Nro. 3.

Enero es el mes con mayor número de publicaciones, el 34\% de los tuits corresponden a este mes, octubre tiene el 24\%, noviembre el $23 \%$ y en diciembre se publican el $19 \%$ de tuits propios. Al igual que en Facebook, los contenidos publicados son en su mayoría informativos y partidarios, principalmente en el mes de enero, cuando se publican contenidos relativos a la Consulta Popular que se celebró en el mes siguiente. Es más, un gran número de asambleístas tienen enlazadas sus cuentas de Twitter y Facebook de forma que los contenidos son exactamente los mismos.

\section{CONCLUSIONES}

Los asambleístas ecuatorianos tienen presencia en medios sociales en un $61 \%$ en Facebook y $56 \%$ en Twitter, lo que quiere decir que hay alrededor de un $40 \%$ de legisladores que no participan en medios sociales (o al menos no enlazan sus perfiles en el sitio web de la Asamblea Nacional), por lo que se limita casi a la mitad, la posibilidad de conocer las necesidades de la ciudadanía y por ende de la aplicación teórica expuesta que el uso de las TIC facilita la bidireccionalidad de la comunicación y la participación ciudadana. La participación en la plataforma instagram es aún menor, sólo el 20\% de los asambleístas tienen una cuenta en esta red muy utilizada principalmente por los jóvenes, otro público limitado de comunicarse con los legisladores a través del uso de la tecnología.

La Asamblea Nacional pone a disposición de los legisladores un blog corporativo, que aunque es limitado para generar retroalimentación con los lectores, tampoco es utilizado por los honorables. Solo el $45 \%$ registra participación de los cuales apenas el 8\% postea semanalmente, los demás lo hacen cada mes o incluso en un período mayor. El blog personal tampoco es una herramienta comunicativa utilizada por los asambleístas, a pesar de ser un elemento importante en los motores de búsqueda de información. Sólo el 12\% de legisladores enlazan un blog, pero de ellos más del 50\% no se interesan por publicar sino eventualmente, algunos no lo han hecho desde que asumieron su curul, es decir lo utilizaron solamente como elemento de campaña electoral.

En Facebook y Twitter los asambleístas que tienen cuentas en dichas redes, sí publican con frecuencia. Más del 70\% en Facebook y del 80\% en Twitter lo hacen diariamente, con un promedio de participación cercano a una publicación por día, aunque en dicha media influyen ciertos valores altos de los asambleístas más activos que superan las 2 publicaciones diarias.

En el promedio de publicación también inciden los altos índices del mes de enero de 2018, que es el de mayor publicación tanto en Facebook como en Twitter, superando los 10 puntos porcentuales con respecto al segundo 
mes en número de publicaciones. Enero tiene gran flujo de contenidos partidistas, dado que los asambleístas mayoritariamente publicaron en este mes información relativa a su posición electoral respecto de la Consulta Popular que se desarrolló en febrero, ratificando que los asambleístas ecuatorianos utilizan los medios sociales, principalmente para fines electorales.

Existe una decena de asambleístas que tienen un número de seguidores mayor a los cincuenta mil, pero aproximadamente el 60\% de los asambleístas se mueven en los rangos de 1.001 a 5.000 y más de 10.000, tanto en Facebook como en Twitter. Es un número alto de personas que buscan mantener comunicación con sus legisladores, punto para que ellos pongan atención en cuánto y cómo responden a esa expectativa.

Si bien las publicaciones en Facebook y Twitter son frecuentes, el estilo y contenidos de las mismas son verticales, unidireccionales, informativas y partidistas. Las publicaciones en enero son mayoritariamente partidistas y electorales, pero en general son de carácter informativo, con imágenes en primer plano del asambleísta en medios de comunicación, intervenciones plenarias o reuniones de trabajo. Es decir, se utiliza como un canal informativo del parlamentario, pero no como un medio de diálogo entre la autoridad y los ciudadanos. Otra vez no se aplica la bidireccionalidad y cercanía del uso de las TIC que los teóricos de la comunicación ponderan.

Estudios similares han sido aplicados en otros países, principalmente de Europa, para medir el uso de las TIC por parte de los legisladores. En esta ocasión se hace una comparación con el estudio realizado por (Almansa-Martínez, 2017) sobre el uso de los medios sociales por parte de los parlamentarios españoles en las tres últimas legislaturas.

Respecto del uso de blogs, los resultados españoles son muy parecidos a los ecuatorianos, el uso de este medio es descendente, el 8\% de los legisladores españoles mantienen un blog frente al 12\% de asambleístas ecuatorianos. La frecuencia de publicación también es similar, los post se publican en periodos mayores a un mes.

En Facebook y Twitter las cosas son diferentes, el $86 \%$ de los diputados españoles están activos en al menos una de estas redes, lo que dista en más del $25 \%$ de la realidad ecuatoriana, que tiene presencia de $61 \%$ en Facebook y $56 \%$ en Twitter. Por otra parte, la red preferida de los españoles es Twitter, los ecuatorianos están en mayor número en Facebook, red que ha descendido notablemente en el uso de los diputados españoles. Los contenidos también tienen similitud, son principalmente informativos y partidistas. En el número de seguidores los ecuatorianos se mueven mayoritariamente en el rango más de 10.000 mientras que los españoles lo hacen en el rango $1.001-5.000$ La frecuencia de publicación en Twitter tiene la misma tendencia, aunque los asambleístas ecuatorianos que tuitean diariamente son el 82\% en España lo hacen el 66\% de los legisladores. 


\section{BIBLIOGRAFÍA}

Almansa-Martínez, A. (2017). ¿Parlamentarios 2.0? Análisis de las tres últimas legislaturas en España. En I. Crespo (Presidencia), VI Congreso ALICE, Comunicación y Crisis Política: el reto democrático. Bogotá.

Asamblea Nacional República del Ecuador. (2018). Pleno-Asambleístas. Sitio oficial de la Asamblea Nacional de Ecuador. Quito, Ecuador. Consultado el 28 de febrero de 2018, de www.asambleanacional.gob.ec/es/ pleno-asambleistas

Canel, M. J. (1999). Comunicación Política. Una guía para su estudio y práctica. Tecnos.

Castillo-Esparcia, A., \& Almansa-Martínez, A. (2014). Comunicación Institucional en España. Estudio del uso que los diputados españoles hacen de las TIC en sus relaciones con la ciudadanía. Chasqui Revista Latinoamericana de Comunicación (126), 22-30.

Coterón Molina, J. (2016). La Comunicación 2.0. Revista española de comunicación en salud, 115-119.

Gómez Céspedes, L. (2016). Ciberdemocracia: comunicación política en twitter. Poliantea, 12(22), 179-208.

Grunig, J.E., \& Hunt, T. (1984). Managing public relations. Harcourt Brace Jovanovich College Publishers.

Gutiérrez-Rubí, A. (2015). La transformación digital y movil de la comunicación política. Barcelona: Ariel.

Menéndez, L. (2008). Blogs corporativos. El lado humano de las empresas. Escritura Pública (52), 22-24.

Monteiro, R., Vera, L., \& Vaca Narvaja, H. (2017). Comunicación política y redes sociales en Argentina. Revista mexicana de comunicación, 1(140).

Pérez, I. (2009). La comunicación política en perspectiva. Comunicación y ciudadanía,0(1). Recuperado de http://revistas.uexternado.edu.co/index. php/comciu/article/view/1824

Selva-Ruiz, D., \& Caro-Castaño, L. (2017). Uso de instagram como medio de comunicación política por parte de los diputados españoles: la estrategia de humanización en la "vieja" y la "nueva" política. El profesional de la información, 26(5), 903-915.

Tuñez, M., \& Sixto, J. (2011). Redes sociales, política y compromiso 2.0: la comunicación de los diputados españoles en Facebook. Revista Latina de comunicación social (66), 210-246. 